\title{
TeACHING AN ADVANCED ENGINEERING MOOC: LESSONS LEARNED
}

\author{
Jeffrey Harris ${ }^{1}$, William Heikoop ${ }^{2}$, Allison Van Beek ${ }^{3}$, and James S. Wallace ${ }^{1}$ \\ ${ }^{1}$ Department of Mechanical \& Industrial Engineering, University of Toronto \\ ${ }^{2}$ Online Learning Strategies, University of Toronto \\ ${ }^{3}$ Faculty of Applied Science \& Engineering, University of Toronto \\ jharris@mie.utoronto.ca, wallace@mie.utoronto.ca
}

\begin{abstract}
Massive Open Online Courses (MOOCs) allow anyone in the public to learn from professors at universities across the world. An internet connection is the only requirement to participate in a MOOC. In engineering, the majority of MOOCs are targeted at selflearners, and consequently most courses are based on introductory undergraduate courses. The University of Toronto offered its first advanced engineering MOOC entitled, "Wind, Waves \& Tides" based on a mixed fourth-year undergraduate and graduate level course. A total of 11,723 students registered in the course, and 617 students completed the course in its entirety. The following paper describes the experience of teaching a niche interest MOOC and the lessons learned throughout the endeavour.
\end{abstract}

Keywords: MOOC, online learning, distance learning, mechanical engineering, alternative energy, Coursera

\section{INTRODUCTION}

The prevalence of massive open online courses (MOOCs) has recently grown as a way of making highquality education freely available to the population-atlarge. This new media helps to serve universities' broad objective of promoting higher learning and sharing knowledge.

Early providers of MOOCs included Stanford University, MIT, and Harvard. Professors from Stanford developed the for-profit Coursera platform [1], and MIT and Harvard developed the non-profit edX platform [2].

Some institutions have been cautious about offering MOOCs because they fear that free MOOCs would directly compete with their existing courses and therefore threaten their business model [3-5]. In reality, there has been no evidence that the proliferation of MOOCs has resulted in declining university enrollments. In fact, the majority of participants in MOOCs already have a university degree. In 32 MOOC sessions offered by University of Pennsylvania, $83 \%$ of participants already had a post-secondary degree [6]. Similarly, in science, technology, engineering, and math (STEM) courses offered by MIT and Harvard, $61 \%$ of participants already had a Bachelor's degree [7].

The University of Toronto is the midst of its third year offering MOOCs under the Open UToronto initiative. The university has partnership agreements with Coursera and edX platforms, and in its first two years it offered 14 courses with a total of 528,847 registrants [8]. The majority of the university's MOOC offerings have been introductory level courses targeted towards self-learners.

In the fall of 2014, we delivered, Wind, Waves and Tides: Alternative Energy Systems, the first advanced engineering MOOC offered by the University of Toronto and second MOOC offered by the Faculty of Applied Science \& Engineering. The MOOC was based on a portion of an alternative energy systems credit course offered as a technical elective for final-year undergraduate students or beginning graduate students. Therefore, there were several recommended prerequisites for the MOOC an unusual attribute for a MOOC.

Since an advanced engineering course is a niche type of MOOC, it is interesting to understand who takes this type of course, how students take the course, the challenges of teaching the course, and lessons learned from the experience. We had three concerns prior to the start of the MOOC: 1) that there wouldn't be enough demand for such a specialized topic, 2) that the prerequisites would limit participation, and 3) that the 7 week course length would be a deterrent, i.e. a larger time commitment than prospective students would be willing to make. 


\section{COURSE DESIGN}

Wind, Waves and Tides: Alternative Energy Systems was delivered over 7 weeks on the Coursera platform. The University of Toronto's MOOC design guidelines [8] were used to help shape the structure of the course. General best-practices for teaching a MOOC are welldocumented [9-11], and many more guidelines are easily available with a simple internet search.

\subsection{Course structure}

Wind, Waves and Tides was divided into three thematic modules. The Wind and Waves modules were subdivided into parts, by topic, as shown in Table 1. Each part started with an introductory video, followed by approximately 5 additional lectures to explore the topic in depth.

The MOOC lecture videos were targeted to be roughly 10-15 minutes in length, a duration identified as effective by previous researchers [12]. Depending on topic, however, individual videos varied in length from 7 to 26 minutes. The Coursera platform has very comprehensive analytic features, which made it possible to easily track on a daily basis, the number of participants who watched each video or completed an assessment.

Many videos contained embedded multiple choice quizzes, consisting of quantitative problems that were adapted from credit course tutorials and homework assignments. These embedded quizzes were included to help each student assess whether he/she understood the lecture material; they were not graded and therefore served as formative assessment. The advantage is that the embedded quizzes provide immediate feedback for comprehension and allow students to monitor the quality of their own work, without the need for active course staff participation [13]. The embedded quizzes were set up so that incorrect answers revealed hints about the error made or even an explanation (including images or figures) of the error if the question is more complex. Additionally, students were encouraged to post on the course discussion board and relate the lecture material to examples specific to their local geography.

\subsection{Assessment}

The course grade was composed of quizzes (60\%), a peer-assessed assignment (15\%), and a final exam (25\%). In total, there were 6 graded multiple choice quizzes. The quiz questions were similar to the practice questions embedded into the lecture videos, and students were able to attempt each quiz multiple times. The peer assessed assignment was designed to connect renewable energy,
Table 1: Outline of course topics

\begin{tabular}{l}
\hline Module 1: Wind Energy \\
\hline A. Wind sources and influences \\
B. Fundamentals of wind energy technology \\
C. Predicting wind turbine output \\
D. Economic and environmental issues \\
E. Case studies \\
\hline Module 2: Wave Energy \\
A. Wave energy fundamentals \\
B. Wave energy converters \\
\hline Module 3: Tidal Energy \\
\hline
\end{tabular}

planning, and local concerns specific to each student's location. It consisted of a short written composition, approximately 500 words. After the submission deadline, peers graded each other's work using the provided rubric. The final exam consisted of questions similar to those in the quizzes, and students were allowed up to two attempts.

A grade of $60 \%$ or higher was required for students to earn a Statement of Accomplishment. Note that Wind, Waves and Tides followed common MOOC practice in that all assessments were carried out by machine grading or by peer-assessment due to the large number of students enrolled. As well, the difficulty of the questions and problems was substantially reduced, both to facilitate machine grading and in recognition of the expected wide range of student backgrounds and ability compared to the students taking the regular university credit course. Similarly, the pace was reduced, with the MOOC duration almost twice that of the time allocated to the material in the regular credit course.

\section{WHO PARTICIPATED}

During the session of this course, 11,723 students registered in the course. As of April 8, 2015, an additional 1982 students had registered for the course in "archive mode", in which they can access the course materials but are not evaluated. A total of 6,296 different people had watched at least one lecture.

Registered students were from 174 different countries (based on IP address), with $44 \%$ from emerging economies. By continent, Europe provided the largest share of registrants $(31 \%)$, followed by North America (26\%), Asia (25\%), South America (9\%), Africa (7\%), and Oceania (2\%). By country, the United States accounted for the largest share of registrants $(17 \%)$, followed by India (10\%), Brazil (5\%), Canada (4\%), Spain (4\%), the United Kingdom (4\%) and Egypt (3\%). The remaining $53 \%$ of the students were from 167 countries, illustrating the tremendous diversity of student backgrounds. 
Table 2: Professional background of course participants

\begin{tabular}{|l|c|c|c|}
\hline $\begin{array}{l}\text { Which of the } \\
\text { following } \\
\text { characterizes } \\
\text { you? }\end{array}$ & $\begin{array}{c}\text { Distribution } \\
\text { of survey } \\
\text { respondents }\end{array}$ & $\begin{array}{c}\text { Distribution } \\
\text { of survey } \\
\text { respondents } \\
\text { who } \\
\text { completed } \\
\text { the course }\end{array}$ & $\begin{array}{c}\text { Completion } \\
\text { rate of } \\
\text { students who } \\
\text { intended to } \\
\text { complete }\end{array}$ \\
\hline Student & $33.1 \%$ & $29.1 \%$ & $37 \%$ \\
\hline Professional & $34.6 \%$ & $44.3 \%$ & $51 \%$ \\
\hline Researcher & $5.9 \%$ & $6.6 \%$ & $48 \%$ \\
\hline $\begin{array}{l}\text { Academic / } \\
\text { professor }\end{array}$ & $2.3 \%$ & $1.6 \%$ & $31 \%$ \\
\hline $\begin{array}{l}\text { Lifelong } \\
\text { learner }\end{array}$ & $21.5 \%$ & $16.1 \%$ & $36 \%$ \\
\hline $\begin{array}{l}\text { None of the } \\
\text { above }\end{array}$ & $2.5 \%$ & $2.2 \%$ & $36 \%$ \\
\hline
\end{tabular}

\subsection{Course completion rates}

Early criticisms of MOOCs focused on their low completion rates of 5 to $15 \%$, using a similar metric to "dropout rates" that are used to evaluate university degree courses [14]. Completion rate is perhaps a metric that should be weighted less, as MOOC participants do not take courses with the purpose of earning a degree: curiosity and job advancement are the top two reasons why students enroll in a MOOC [6]. Furthermore, many students intend to audit the course, intend to only complete a portion of the course, or enroll in a MOOC before committing to the course [15]. Therefore, more recently, completion rates are examined in the context of student intent. In a study of 9 HarvardX courses, $22 \%$ of students who intended to complete a course did so [15]. This metric was more broadly applied to 35 HarvardX and MITx courses, and the completion rate was $24 \%$ for students who intended to complete the course [7].

Prior to the start of the course, 885 students responded to a survey. We asked students about their intent to complete the course. We also asked students their professional background and whether they had previously studied engineering to allow us to understand the course demographics.

In Wind, Waves and Tides, 617 out of 11,723 registrants completed the course, making the completion rate $5.2 \%$. By tracking the students who responded to the pre-course survey, we calculated that the completion rate was $42 \%$ for those who intended to complete the course. This is significantly higher than reported averages $[7,15]$.

\subsection{Characteristics of course participants}

In Table 2, we show the distribution of course participants and completion rate (of students with the intent of completing the course) by their professional background. Participants consisted mostly of students,
Table 3: Engineering background of course participants

\begin{tabular}{|c|c|c|c|}
\hline $\begin{array}{l}\text { Have you } \\
\text { studied } \\
\text { engineering } \\
\text { before? }\end{array}$ & $\begin{array}{c}\text { Survey } \\
\text { respondents }\end{array}$ & $\begin{array}{c}\text { Survey } \\
\text { respondents } \\
\text { who } \\
\text { completed } \\
\text { the course }\end{array}$ & $\begin{array}{l}\text { Completion } \\
\text { rate of } \\
\text { students } \\
\text { who } \\
\text { intended to } \\
\text { complete } \\
\end{array}$ \\
\hline $\begin{array}{l}\text { Yes, I have a } \\
\text { degree in } \\
\text { Engineering or } \\
\text { significant } \\
\text { work } \\
\text { experience }\end{array}$ & $59.2 \%$ & $72.5 \%$ & $67 \%$ \\
\hline $\begin{array}{l}\text { Yes, I have } \\
\text { taken some } \\
\text { courses in } \\
\text { Engineering or } \\
\text { have some } \\
\text { work } \\
\text { experience }\end{array}$ & $16.5 \%$ & $13.3 \%$ & $35 \%$ \\
\hline $\begin{array}{l}\text { Yes, one of my } \\
\text { courses had a } \\
\text { unit on } \\
\text { Engineering }\end{array}$ & $5.2 \%$ & $5.1 \%$ & $38 \%$ \\
\hline $\begin{array}{l}\text { Yes, I have } \\
\text { done some } \\
\text { personal } \\
\text { reading or } \\
\text { exploring on } \\
\text { my own. }\end{array}$ & $5.3 \%$ & $3.5 \%$ & $34 \%$ \\
\hline No, not at all & $13.2 \%$ & $5.4 \%$ & $18 \%$ \\
\hline
\end{tabular}

professionals, and lifelong learners. For participants intending to complete the course, the completion rates were substantially higher for professionals and researchers than they were for other categories.

In Table 3, we show the distribution of course participants and completion rate (of students with the intent of completing) by their level of engineering experience. The majority of participants had an engineering degree or significant engineering work experience; however, there was also a substantial number of students who with no engineering experience. The MOOC targeted an audience with some engineering education or experience, and the recommended prerequisites included thermodynamics, fluid mechanics, and heat transfer. Therefore it was expected that participants with little or no previous engineering education would be challenged. Indeed, the completion rate was the lowest for participants with no engineering experience who intended to complete the course. At the other end of the spectrum, the completion rate was very high for participants who intended to complete the course and had an engineering degree or significant work experience. 


\section{LESSONS LEARNED}

\subsection{Advanced courses with pre-requisites can be successful}

Initially, we were curious how the reception would be for an advanced course with several technical prerequisites. With pre-requisites in place, the course attracted a large number of registrants, and the majority of participants did have an engineering education. The students who met the pre-requisites were most likely to complete the course, and in total, 617 students completed the course. For comparison the only previous engineering MOOC offered by the University of Toronto had no prerequisites, and 458 students completed that course [8].

On the other hand, approximately $13 \%$ of students had no engineering background and did not likely meet the prerequisites. Indeed, a number of students self-identified as non-engineers (e.g. architect, construction company administrator) on the discussion boards but were sufficiently interested in the topic to try anyway and asked for patience from other students. The freedom to take any course could be considered a MOOC advantage as it allows students to explore new areas without the academic consequence of failure. Accordingly, a few students posted on the discussion board asking for help on very basic matters such as converting between different units. These posts, however, were in the minority. What was especially interesting to note was the highly supportive response of more knowledgeable fellow students, who in many cases patiently supplied the missing information in detail without any hint of condescension. In the absence of student response, course staff responded to those posts helpfully. Furthermore, students told us that 7 weeks was a good length for the course. In a post-course survey, 98 out of 136 course completers said the course length was "just right", and only 9 course completers said the course was too long. Additionally, only 4 out of 21 noncompleters agreed that a shorter course would have made them more likely to complete the course.

\subsection{Make expectations very explicit for peer- assessed assignments}

Peer-assessed assignments are a terrific means of developing student critical thinking and assessment skills. For alternative energy systems, it provides an opportunity to explore non-technical issues, e.g. regulatory and approval processes, environmental impact, and societal acceptance. However, the assignment instructions and marking rubric were based on previous experience with senior undergraduates and beginning graduate students in a regular university course and failed to account for the hugely diverse backgrounds and levels of the MOOC students.
For future courses, we recommend that expectations for the peer-assessed assignment be clearly stated in some detail, especially the expectations for citing references. With a diverse group of participants in the course, the expectations for citing references were also diverse. In some cases, authors described a local energy project in their own words, and they were penalized during the peer evaluation because the lack of citations, the absence of information source documentation, was interpreted as a sign of poor quality. Adding explicit instructions to the assignment description and to the marking rubric would greatly benefit authors and evaluators. Due to the significant number of students with weak English language skills, the marking rubric must provide a means of evaluating communication, e.g. organization, logical presentation of ideas, while downplaying English language skills.

In a handful of cases, blatant plagiarism was apparent and those students received a mark of zero for the peerassessed assignment. Coursera does have an Honor Code to which students agree when they register. However, to minimize the cases of plagiarism, we recommend reminding students of the Honor Code in the assignment instructions. It would also be a good idea to provide a link to resources that help set expectations. For example, our Faculty has prepared some excellent online tutorial material on accurate documentation that could be referenced in the assignment instructions [16].

\subsection{Incorporating MOOCs into the classroom}

Through the Open UToronto Initiative, the University of Toronto aims to leverage the content created for MOOCs and integrate it into its existing degree-credit courses [8]. Indeed, all of the course material developed for Wind, Waves, and Tides, was integrated into the 2015 Winter term offering of MIE 515 Alternative Energy Systems, a credit course for final year undergraduate and beginning graduate students. This integration was facilitated by the intentional design of MOOC slide templates, logos, etc, that were either generic by topic or easily rebranded for use in MIE 515. The seven week Wind, Waves, and Tides MOOC became 3 course modules that spanned four weeks in MIE 515. An additional 7 course modules were created for MIE 515, using the techniques and practices that were developed to produce the material for the MOOC. Due to time and resource constraints, it was not possible to implement the embedded quiz feature employed with the MOOC, into the MIE 515 lecture videos, but this is a goal for the next MIE 515 offering.

MIE 515 has more complex problem sets and assignments, including two simulations evaluating prospective alternative energy systems installations. These greatly enrich the student learning experience, but they do 
require considerable course staff time for evaluation, a resource not available for MOOCs.

MIE 515 has been offered online since 2011 [17], but effectively evolved into an online course as an experiment rather than being designed as an online course. The MOOC provided a fast-paced opportunity to explore online delivery and assessment techniques.

The value of peer-assessed assignments was readily apparent during the MOOC, despite the issues with assignment instructions and marking rubric design. Many MOOC students expressed their appreciation on the discussion boards for the highly constructive and detailed feedback they received from their peers. Accordingly, three peer-assessed assignments were implemented in MIE 515 for the Winter 2005 term to replace marked participation in online discussion boards. The latter was ineffective at developing critical assessment skills as students were reluctant to provide any criticism of their classmates in a public forum.

The peer-assessed assignments were easily implemented using the purpose-designed software peerScholar [18]. There are 3 phases to a peerScholar assignment: CREATE, ASSESS, and REVISE/REFLECT. In the CREATE phase, students develop and submit an initial version of their assignment. In the ASSESS phase, peerScholar randomly and anonymously sends the assignment to a specified number of classmates ( 3 were used for MIE 515) for comment and evaluation using the rubric provided by the course instructor. The comments and evaluations are then returned anonymously to the original author. The REVISE/REFLECT phase provides the author with the opportunity to reflect on the peer assessment and revise their assignment accordingly. For MIE 515, the final assignment submitted at the end of this phase was then marked by course staff. As a result of the peer assessment process, the quality of the final assignments has been very high. As of the date of submitting this manuscript, the course evaluations for MIE 515 have not yet been released, and these evaluations will provide the student impressions of the peer-assessed assignments.

\section{CONCLUDING REMARKS}

Our experience delivering Wind, Waves and Tides, showed that our three initial concerns were unfounded. There was substantial demand for a very specialized advanced engineering course. Indeed, a number of MOOC participants requested a more advanced follow-up course or courses on other alternative energy topics.

Second, the pre-requisites were not a limitation Our experience is consistent with other studies [6,7] that have shown that MOOC participants are, in general, highly educated. On the whole, students had the background knowledge necessary to complete the course. This advanced engineering MOOC tended to attract professionals with engineering degrees, and students in this demographic had the highest completion rates.

Finally, the seven week duration doesn't appear to have been a limitation either. Student feedback confirmed that the course length was suitable. As noted previously, completion rates for the student who said initially that they intended to complete the course compare favorably with data available from other MOOCs.

\section{Acknowledgements}

The authors gratefully thank the Faculty of Applied Science \& Engineering, Open Learning Strategies, the University of Toronto Libraries, and the Open Course Initiative Fund at the University of Toronto for making the Wind, Waves and Tides MOOC possible.

\section{References}

[1] Coursera http://www.coursera.org

[2] edX http://www.edx.org

[3] B. S. Balaji and A. Chandra Sekhar, "The various faces of MOOC," 2013 IEEE International Conference in MOOC, Innovation and Technology in Education (MITE), pp. 139142

[4] Flora S. Tsai, "The state of massive open online courses (MOOCs) in engineering education: where do we go from here?" Proc. of the 120th ASEE Annual Conference \& Exposition (Atlanta, USA, 23026 June 2013), 16 pp., 2013.

[5] "The attack of the MOOCs," The Economist, 20 July 2013. Available as of 10 April 2015 from http://www.economist.com/node/21582001/

[6] G. Christensen, A. Steinmetz, B. Bennett, D. Woods, E. J. Emanuel, "The MOOC phenomenon: who takes massive open online courses and why?" University of Pennsylvania, 2013. Available as of 10 April 2015 from http://ssrn.com/abstract=2350964

[7] A.D. Ho, I. Chuang, J. Reich, C. Coleman, J. Whitehill, C. Northcutt, J. Williams, J. Hansen, G. Lopez, and R. Petersen, "HavardX and MITx: Two years of open online courses," HarvardX Working Paper No. 10, 37 pp., 2015. Available as of 8 April 2015 from http://dx.doi.orgg/10.2139/ssrn.2586847

[8] L. Harrison, "Open UToronto MOOC initiative: Report on second year of activity" University of Toronto, 2014. Available as of 9 April 2015 from http://www.ocw.utoronto.ca/wpcontent/uploads/2014/09/MOOC-Y2-Report-September2014.pdf 
[9] "Massively Open Online Courses (MOOC) Design and Development Process Guidelines" Open UToronto, 2013. Available as of 10 April 2015 from http://www.ocw.utoronto.ca/wpcontent/uploads/2013/05/MOOC-Design-and-DevelopmentGuidelines-2-Feb-2013.pdf

[10] M. Bali, "MOOC Pedagogy: Gleaning Good Practice from Existing MOOCs," MERLOT Journal of Online Learning and Teaching, vol. 10, no. 1, pp. 44-46, 2014. Available as of 12 April 2014 from http://jolt.merlot.org/vol10no1/bali_0314.pdf

[11] A.M.F. Yousef, M.A. Chatti, U. Schroeder, and M. Wosnitza, "What drives a successful MOOC? An empirical examination of criteria to assure design quality of MOOCs," Proc. of the 2014 IEEE 14th International Conference on Advanced Learning Technologies (ICALT), (Athens, Greece 7-9 July 2014), pp. 44-49, 2014.

[12] P. Guo, "Optimal video length for student engagement," $e d X$ blog, 2013. Available as of 16 April 2015 from https://www.edx.org/blog/optimal-video-length-studentengagement

[13] D.R. Sadler (1989). "Formative assessment and the design of instructional systems," Instructional Science, 18, 119-144, Kluwer Academic Publishers, Netherlands.

[14] T. Daradoumis, R. Bassi, F. Xhafa, S. Caballé, “A review on massive e-learning (MOOC) design, delivery and assessment, " Proc. of 2013 Eighth International Conference on P2P, Parallel, Grid, Could and Internet Computing (3PGCIC), (Compiègne, France, 28-30 October 2013) pp. 208-213, 2013.

[15] J. Reich, "MOOC completion and retition in the context of student intent," Educause Review, 2014. Available as of 9 April 2015 from http://www.educause.edu/ero/article/mooccompletion-and-retention-context-student-intent

[16] Engineering Communication Centre, Faculty of Applied Science and Engineering "Accurate Documentation," Available as of 17 April 2015 from http://www.engineering.utoronto.ca/Directory/students/ecp/ handbook/accurate.htm

[17] J.S. Wallace and H. Dhariwal, "Experience with Online Delivery of an Engineering Technical Elective Course," Third Annual Canadian Engineering Education Association (CEEA) Conference, Winnipeg, Manitoba, June 17-20, 2012.

[18] PeerScholar http://www.peerscholar.com/ 